\title{
Successful endoscopic submucosal dissection of a large juvenile polyp in the stomach of an infant
}

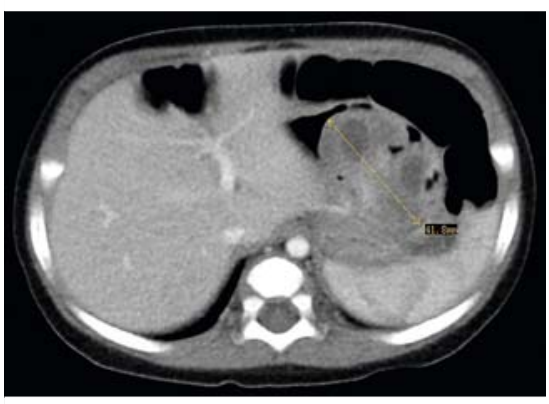

- Fig. 1 Enhanced abdominal computed tomography showing a $4.2-\mathrm{cm}$ mass of mixed density in the stomach of a 5-month-old male infant.

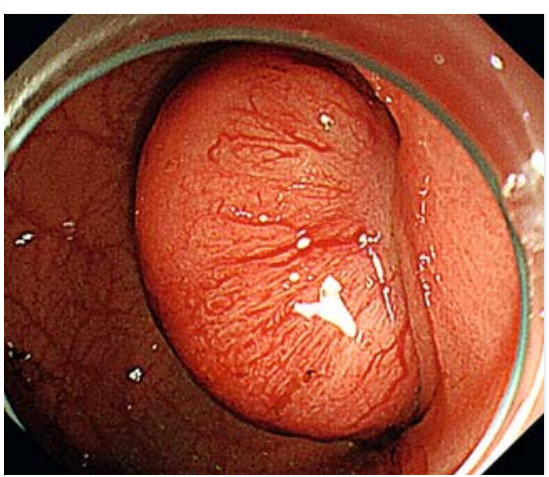

- Fig. 2 Gastroscopy revealing a polyplike mass in the posterior wall of the upper stomach.

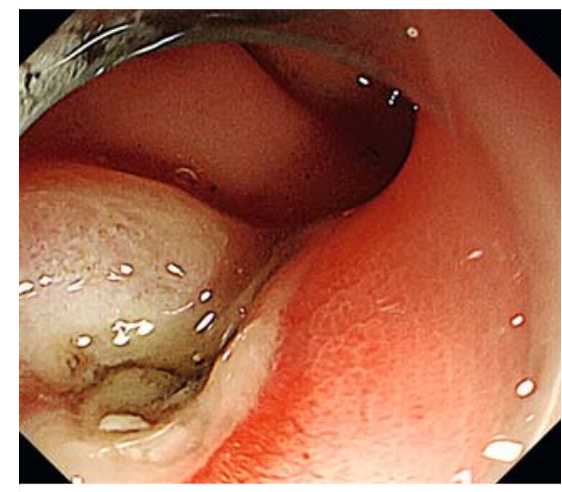

- Fig. 3 Clear surface of the wound after dissection of the mass from the stomach.

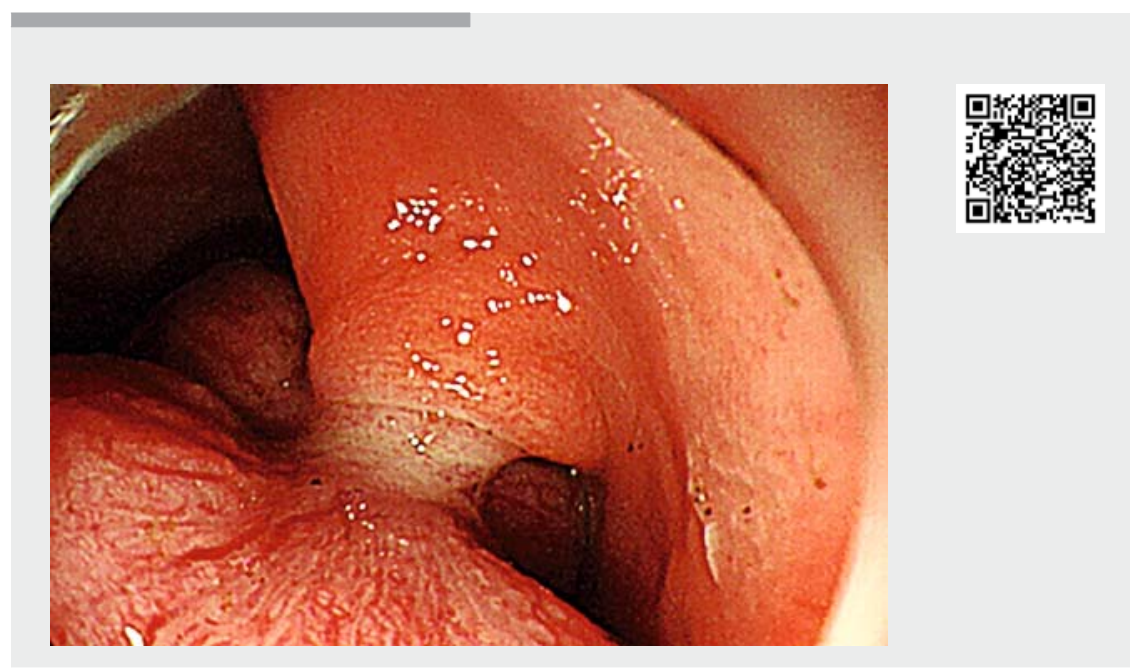

Video 1 Endoscopic submucosal dissection in a 5-month-old infant.

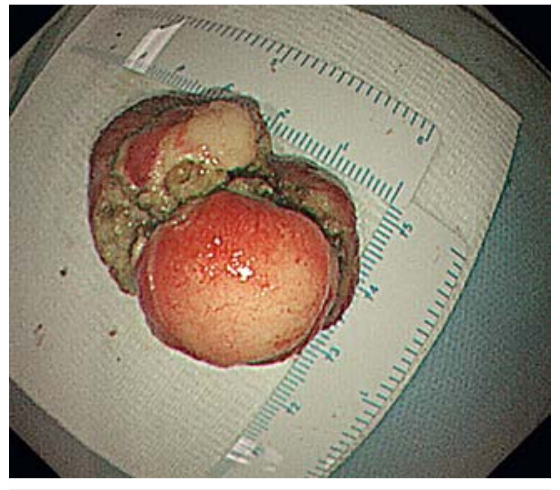

Fig. 4 The resected polyp (as reassembled), measuring $4.2 \times 3.0 \mathrm{~cm}$.

A 5-month-old male infant suffered from massive upper gastrointestinal bleeding that resulted in a hemoglobin level of $48 \mathrm{~g} / \mathrm{L}$ when he was referred to our hospital. A 4.2-cm mass of mixed density was detected in the stomach by enhanced abdominal computed tomography ( $\triangleright$ Fig. 1). No family history of polyposis was recorded and there were no dark spots on the lips, hands, or feet. Gastroscopy showed a rounded and smooth-contoured polyp-like mass in the posterior wall of the upper stomach

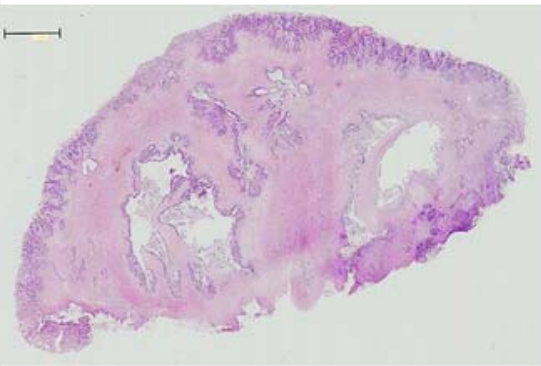

Fig. 5 Histopathological characteristics of the solitary juvenile polyp, which presented a marked increase in the stromal cell compartment with predominant smooth muscle, distorted and dilated crypts, and inflammatory changes in the lamina propria (H\&E staining).

(> Fig.2). Endoscopic submucosal dissection (ESD) was indicated because of the presence of the large polyp ( Video 1). Abundant angiogenesis of the mass led to bleeding during the ESD procedure. Coagrasper hemostatic forceps were used for hemostasis. After the polyp had been resected from the stomach ( $\triangleright$ Fig.3), the mass was cut into small pieces with a hook knife and the pieces were taken out individually with a 
snare ( $\triangleright$ Fig.4), because the mass was too large to pass through the cardia whole. Finally, the incision was closed with clips. Histopathological examination of the mass revealed characteristics of hamartomatous polyps that presented as a marked increase in the stromal cell compartment with predominant smooth muscle, distorted and dilated crypts, and inflammatory changes in the lamina propria, indicating a solitary juvenile polyp ( Fig.5). Follow-up gastroscopy performed a month later showed proper wound healing and no residual mass. Solitary juvenile polyps (size range: $3 \mathrm{~mm}$ to $2 \mathrm{~cm}$ ) are common in the colorectum but rarely reported in the stomach, especially in infancy [1]. The patient reported here may be the first and the youngest to present with a large gastric juvenile polyp $(4.2 \mathrm{~cm})$. Successful ESD not only resected the large polyp but also preserved the integrity of this infant's stomach [2]. To the best of our knowledge, he is the youngest patient so far to have undergone ESD.

Endoscopy_UCTN_Code_CCL_1AB_2AD_3AB

\section{Acknowledgements}

The authors acknowledge receiving funding from the Chengdu Science and Technology Bureau (China) (2017-CY02-00023-GX).
Competing interests

The authors declare that they have no conflict of interest.

\section{The authors}

Zhiyin Huang', Hui Gong', Linjie Guo', Yongmei $\mathrm{Xie}^{2}$, Bing $\mathrm{Wei}^{3}$, Chengwei Tang ${ }^{1}$, Bing $\mathrm{Hu}^{1}$

1 Department of Gastroenterology, West China Hospital, Sichuan University, Chengdu, China

2 Department of Gastroenterology, West China Women's and Children's Hospital, Sichuan University, Chengdu, China

3 Department of Pathology, West China Hospital, Sichuan University, Chengdu, China

\section{Corresponding author}

\section{Bing Hu, MD}

Department of Gastroenterology, Sichuan University West China Hospital, No. 37, Guo Xue Xiang Chengdu, Sichuan 610041, P. R. China

Fax: +86-28-85422387

hubingnj@163.com
References

[1] Vyas M, Yang X, Zhang X. Gastric hamartomatous polyps - review and update. Clin Med Insights Gastroenterol 2016; 9: 3-10

[2] Jelsig AM, Qvist N, Brusgaard K et al. Hamartomatous polyposis syndromes: a review. Orphanet J Rare Dis 2014; 9: 101

\section{Bibliography}

Endoscopy 2021; 53: E376-E377

DOI 10.1055/a-1300-0865

ISSN 0013-726X

published online 3.12 .2020

(c) 2020. Thieme. All rights reserved.

Georg Thieme Verlag KG, Rüdigerstraße 14, 70469 Stuttgart, Germany

ENDOSCOPY E-VIDEOS

https://eref.thieme.de/e-videos

口回 Endoscopy E-Videos is a free

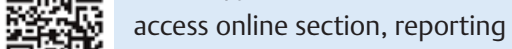
靣辌: on interesting cases and new

techniques in gastroenterological endoscopy. All papers include a high quality video and all contributions are freely accessible online.

This section has its own submission website at https://mc.manuscriptcentral.com/e-videos 